\title{
Geographical Scale, Industrial Diversity and Regional Economic Stability
}

Jing Chen

West Virginia University, jechen@mail.wvu.edu

Follow this and additional works at: https://researchrepository.wvu.edu/rri_pubs

Part of the Regional Economics Commons

\section{Digital Commons Citation}

Chen, Jing, "Geographical Scale, Industrial Diversity and Regional Economic Stability" (2017). Regional Research Institute Working Papers. 34.

https://researchrepository.wvu.edu/rri_pubs/34

This Working Paper is brought to you for free and open access by the Regional Research Institute at The Research Repository @ WVU. It has been accepted for inclusion in Regional Research Institute Working Papers by an authorized administrator of The Research Repository @ WVU. For more information, please contact ian.harmon@mail.wvu.edu. 


\section{Regional Research Institute West Virginia University}

Working Paper Series

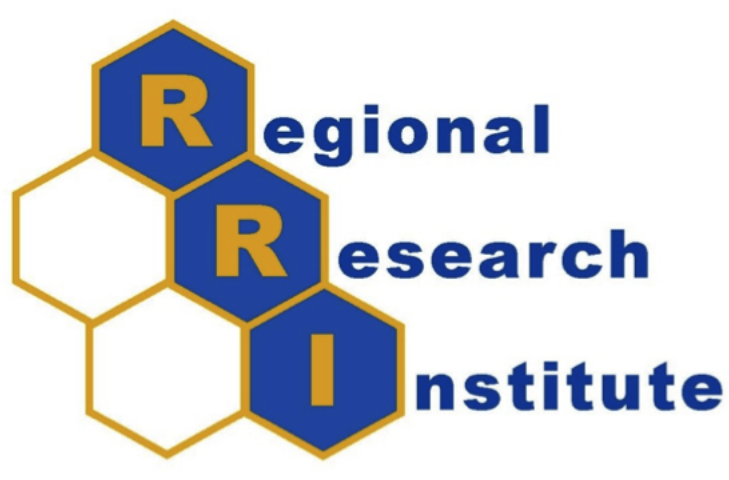

Geographical Scale, Industrial Diversity and Regional Economic Stability

Jing Chen, Graduate Research Assistant, Regional Research Institute and Department of Geology and Geography, West Virginia University

Working Paper Number 2017-03

Date submitted:December 1, 2017

Key words/Codes: Geographical Scale, Industrial Diversity, Economic Stability, Spatial Interactions; C40, R11, O11 


\title{
Geographical Scale, Industrial Diversity and Regional Economic Stability
}

\author{
Jing Chen*
}

December 1, 2017

\begin{abstract}
The empirical relationship between economic diversity and economic stability varies when it is measured at different geographical scales. This paper evaluates the role of geographical scales in assessing this diversity-stability relationship among counties, states, Economic Areas (EAs), metropolitan counties and metropolitan statistical areas (MSAs) in the contiguous U.S. When choosing geographical units to analyze regional economic structure, it is necessary that the geographical units be large enough in population and employment to quantify effectively the regional economic structure. In addition, this paper proposes that geographical units also should be functionally aggregated regions as they better represent spatial interactions than formal regions do, and they consider the possible temporal variations in the boundaries of regional economic structures.
\end{abstract}

${ }^{*}$ Graduate Research Assistant, Regional Research Institute and Department of Geology and Geography, West Virginia University. E-mail: jechen@mail.wvu.edu 


\section{Introduction}

The role of economic diversity ${ }^{1}$ in regional economic development at regional levels has been studied conceptually, theoretically and empirically for a long time, with a recurrent focus on its relationship with regional economic stability (Conroy, 1975; Jackson, 1984; Malizia and Ke, 1993; Deller and Watson, 2016a). According to Malizia and Ke (1993, p. 222), the concept of diversity refers to "the variety of economic activity which reflects differences in economic structure at a specific time", while stability is defined as "the absence of variation in economic activity over time."

Based on these concepts, it is theoretically assumed that diversified economies can exhibit greater stability in their economic performance. This is because their industries are not overly dependent on only a few industries and that they will suffer less from external economic downturns as suggested by, for example, the portfolio theory (Conroy, 1975). This theory originated in finance literature (e.g., Markowitz, 1968) and treats employment in each industry as an individual investment for a given region. Employment for all industries can be viewed as the regions industrial portfolio. As such, it is risky for the portfolio to have only a few investments because it may be seriously affected by specific economic downturns.

The empirical relationship between industrial diversity and economic stability at the regional level has been tested, yet the results are mixed. For instance, a number of authors (e.g., Conroy, 1975; Kort, 1981; Wagner and Deller, 1998 ; Trendle, 2006) confirmed the negative relationship between diversity and instability, whereas others like Jackson (1984), Attaran (1986) and Deller and Watson (2016b) claimed that this relationship is not always significant.

Similarly, a closely related topic in the literature is the effect of economic diversity on regional unemployment. This topic can be viewed from two compelling theoretical perspectives, the portfolio theory (Conroy, 1975) and search theory (Simon, 1988). The portfolio theory suggests that diversity can reduce risk in unemployment and that the positive or negative

\footnotetext{
${ }^{1}$ In this paper, the terms of "industrial diversity" and "economic diversity" are used interchangeably, although there are subtle differences in some literature economic like Malizia and Ke (1993) and Feser et al. (2014).
} 
relationship between economic diversity and stability depends on business cycles. Chiang (2009, p. 952) further explained that "in a prosperous period, a specialized region experiences relatively lower unemployment than a diverse region," while "a specialized region suffers relatively higher unemployment than a diverse region." In contrast, the search theory claims that economic diversity can reduce unemployment because of greater employment opportunities within diversified economies. Based on these theoretical understandings, Malizia and Ke (1993) and Izraeli and Murphy (2003) verified the negative relationship between diversity and unemployment, while Mizuno et al. (2006) found that this relationship is weak and even non-existent in the case of metropolitan areas in Japan.

\section{[INSERT TABLE[1]}

Wagner and Deller (1998) suggested three principal factors in methodology that may lead to an inconsistency between the theoretical assumption and the empirical evidence of the diversity-stability relationship. These factors include (1) the use of highly aggregated geographical data sets, (2) inappropriate measures of regional economic structure, and (3) overly simplistic modeling methods. Previous literature on the economic diversity research, shown in Table 1, reveals that the last two factors have been studied before; for example, Wagner and Deller(1998) and Hong and Xiao (2016) have proposed alternative measures of regional industrial structure, and more advanced modeling techniques for testing the hypothesized relationships, such as spatial econometric models, have been adopted by Trendle (2006) and Deller and Watson (2016a). By comparison, there is little research on how different geographical scales can impact the understanding of regional economic structure and its policy implications for regional economic development, although numerous scholars (e.g., Harvey, 1968; Watson, 1978; Gibson, Ostrom and Ahn, 2000; Ruddell and Wentz, 2009; Schaeffer et al., 2011) have stressed the role of geographical scale as a generic issue in spatial analysis. To this end, this paper contributes to the literature by focusing exclusively on the role of geographical scales and analytical units in evaluating the empirical relationship between industrial diversity and regional economic stability.

The layout of this paper is as follows. In the second section, the investigation of the role of geographical scale in assessing the effect of economic 
diversity draws on three perspectives: (1) scale definitions in spatial analysis, (2) scale-related problems, and (3) analytical units in economic diversity research. The third section describes the methodology of this analysis. After that, results are presented and discussed. Finally, the policy implications and the findings from the analysis are summarized.

\section{Background}

\subsection{The definition of scale in spatial analysis}

The concept of scale has various definitions in spatial, temporal, and other dimensions of regional research. Even though only spatial scale is focused on here, Goodchild (2011) suggested that there are three meanings to this concept. First, the term scale may refer to the cartographic scale or representative fraction, which is calculated as the ratio of a distance on a map to its corresponding distance in the real world. More generally, this ratio is displayed as a scale bar in cartography. A large-scale map covers a smaller area, but with greater detail, whereas a small-scale map covers a larger area with less detail.

By comparison, the second use of the term is the spatial extent of a study region. For example, the spatial extent or scale of West Virginia is much larger than that of New York City. In the context of regional economic development, Ye and Rey (2011) developed a conceptual framework of exploratory space-time analysis in which four potential spatial scales or extents (individual, local, meso and global) could be considered.

Third, scale can also be defined as the spatial resolution or analytical unit of a study. In other words, scale is the smallest distinguishable part of an object (Tobler, 1988) like pixels in a satellite imagery. For this paper, the third meaning of scale is used unless explicitly noted otherwise. In reference to economic diversity research, the spatial resolutions or scales can be counties (Deller and Watson, 2016a), states (Attaran, 1986, Wagner and Deller, 1998), and metropolitan statistical areas or MSAs (Kort, 1981; Malizia and Ke, 1993. Hong and Xiao, 2016). A county-based study usually has finer spatial resolution than a state-based one. Jackson and Sonis (2001) suggested 
that the choice of spatial resolution or analytical unit is often decided by data availability and political considerations in the study of regional economic systems. Yet, data reporting units and political regions are often inconsistent with the boundaries of regional economic systems. This inconsistency can result in two related problems, namely (1) the modifiable areal unit problem (MAUP) as proposed by Openshaw and Taylor (1979) and Openshaw (1984) and (2) the uncertain geographical context problem (UGCoP) suggested by Kwan (2012).

\subsection{Scale-related problems}

The MAUP arises when the analytical units are modifiable in size or spatial arrangement; to be more specific, the MAUP includes two interrelated aspects: the scale problem and the zoning problem (Openshaw, 1984). First, the scale problem occurs when the total number of geographical units changes and causes the statistical properties of aggregated or disaggregated units to vary. This problem has been frequently discussed in connection with the ecological fallacy (Robinson, 1950). In Robinson's study, the correlation between the percentage of native born population and the percentage of illiteracy is positive at the individual level but negative at the census division level, demonstrating that statistical relationships cannot be transferred from one scale to another. Second, the zoning problem refers to the effects resulting from different zoning or spatial aggregation schemes. This is because there are various approaches to aggregating any specified number of zones. Openshaw and Taylor(1979), for example, found that the correlation between age and voting behavior was very different when aggregating counties based on different zoning schemes.

In contrast to the well-known MAUP, the uncertain geographical context problem (UGCoP) has received much less attention (Kwan, 2012). It is different from the MAUP, as it is not about the modifiable units but about the "true spatial configurations." The UGCoP arises when contextual or analytical units that are defined geographically differ from the true geographical contexts, which are usually unknown in most studies to date. For instance, neighborhood regions like census tracts and postal code areas are used as contextual units to detect the geographical distribution of diseases in health research. These regions do not reflect "the actual areas that exert contextual 
influences on the heath outcome under study" (Kwan, 2012, p.959) because the boundaries of peoples activities, such as commuting to work and social interactions, usually are larger than neighborhoods. Besides health research, Kwan (2012) further argued that any study that examines the effects of areabased attributes on geographical phenomena faces the UGCoP.

\subsection{Analytical units in economic diversity research}

The MAUP and the UGCoP can impact economic structure research when different analytical units are used. Based on the previous research, two groups of analytical units have been identified: formal regions and functional regions. Because of data availability and policy relevance, formal or administrative units have been widely used to study the effect of economic diversity as reported by Attaran (1986) and Deller and Watson (2016a, 2016b). Specifically, Attaran(1986) studied the relationship between economic diversity and economic stability based on state-level data sets, which can be seriously affected by the MAUP and the UGCoP. For example, the city of St. Louis in Missouri was built along the western bank of the Mississippi River and shares its boundaries with the state of Illinois. Because state boundaries do not generally hinder economic interactions, the citys businesses might have stronger economic interactions with some businesses in Illinois than with those in the rest of Missouri. These interactions can be local inter-industry flows, face-toface contact in formal business meetings or frequent informal contact, such as lunch meetings, sports activities, or other social occasions. All of these interactions can bring indirect effects to regional economic performance but cannot be reflected meaningfully in state-level data sets. In that sense, states may not be appropriate units to use when assessing the effects of economic diversity.

Similarly, Deller and Watson (2016a, 2016b) as well as others, have used county-level data sets to study regional economic structure. One potential drawback of these data sets, however, is that the employment and population of some counties are not comparable with others, making it almost meaningless to measure their economic structures. For instance, even though some counties in the western U.S. have diverse industries, their economic size is limited and cannot reasonably constitute an "industrial portfolio" that guards against economic downturns as suggested by the portfolio theory (Conroy, 1975) or the agglomeration of economies. In that sense, it might be inap- 
propriate to use counties as geographical units to study regional economic diversity.

Second, a number of authors have used functional regions to study regional economic diversity. Malizia and Ke(1993), and Hong and Xiao (2016), for example, studied MSAs in the U.S., and Trendle(2006) studied local government areas in Australia. In fact, functional regions have been studied for a long time in geography and regional science (e.g., Philbrick, 1957; Nystuen and Dacey, 1961; Fox and Kumar, 1971; Brown and Holmes, 1971). One familiar example of functional regions is U.S. MSAs, which are defined based on population density and commuting patterns. Conceptually, according to Brown and Holmes (1971, p. 58), functional regions are defined based on a greater magnitude of interactions or connections among spatial units within a region than with units outside the region. Based on this definition, it is expected that functional regions can represent economic interactions better than can formal regions. Thus, functional regionsrather than administrative regionsshould be chosen to measure regional economic structure. Although this preference has been explicitly stressed by Jackson (1984), Malizia and Ke (1993) and Trendle (2006), no empirical comparison has been made between these two types of regions. To fill this gap, this paper evaluates the role of different geographical units, including functional and formal regions, in assessing the effect of industrial diversity on regional economic stability.

\section{Methodology}

\subsection{Geographical scales}

There are two groups of geographical units used in this analysis. The first group includes county, state and Economic Area, all of which covers the complete country. County-level data are used to explore the relationship between industrial diversity and economic stability at the most disaggregated level. There are several technical issues that need to be overcome when using county-level data. To ensure consistency, for example, it is necessary to combine 50 independent cities and surrounding counties in Virginia to form 23 county equivalents because of strong interconnections. Some newlyestablished counties like Broomfield, Colorado, were merged with their par- 
ent counties. As a result, a total of 3,079 counties or county equivalents in the lower U.S. were included in the analysis. Next, these counties, or county equivalents, were spatially aggregated into 48 states and the District of Columbia; state is utilized as the second geographical unit. In addition to county and state, the Bureau of Economic Analysis Economic Area (EA) is also used to approach the diversity-stability relationship. Like MSAs, EAs are functional regions as they are defined based on county-level population and commuting flows ${ }^{2}$, As shown in Figure 1a, there are 170 EAs covering the lower U.S.

\section{[INSERT FIGURE 1$]$}

The second areal group considers two geographical units, metropolitan counties (hereafter 'metro-counties) and metropolitan statistical areas. Unlike the geographical units in the first group, metro-counties and MSAs do not cover the whole country and only include metropolitan regions. In total, there are 1,066 metro-counties and 359 MSAs in this analysis. (See Figure 1b.) As defined by the U.S. Office of Management and Budget (OMB), the MSAs contain at least one core urban area with a population of 50,000 or more and adjacent counties with at least $25 \%$ of the workers living in the county while working in the core urban area. Based on this definition, the delineation of MSA boundaries updates regularly, and regional scholars (e.g. Kort, 1981; Malizia and Ke, 1993; Hong and Xiao, 2016) have applied MSAs to analyze regional economic structures.

\subsection{Empirical model}

The empirical model can be described as:

$$
R E I_{i}=f\left(D I V_{i}, C O N T R O L_{i}\right)
$$

where $R E I_{i}$ stands for regional economic instability (REI) defined by Malizia and Ke (1993); $D I V_{i}$ is the independent variable of economic diversity; and $C O N T R O L_{i}$ is a set of control variables. All the variables on the right

\footnotetext{
${ }^{2}$ For more information about the defining process, see Johnson (1995) and Johnson and Kort (2004). The latest two updates of the BEA Economic Areas were made in 1995 and 2004. The 1995 version of EAs was used.
} 
hand side of Equation (1) the state of the regions economy for the base year of 2000, while the dependent variable reveals changes from 2000 to 2014 . Regional economic instability is measured using county level employment from 2000 to 2014 from the Bureau of Economic Analysis. It is calculated as the average deviation of total employment from its trend and divided by trend employment and can be expressed as:

$$
R E I_{i}=\left\{\sum_{i=1}^{N}\left[\left(E_{i t}-E_{i t}^{T r}\right) / E_{i t}^{T r}\right]^{2} / T\right\}^{1 / 2}
$$

where $i$ denotes the region index; $T$ is the number of studying years; $E_{i t}$ is the actual number of workers for region $i$ at time $t$; and $E_{i t}^{T r}$ is the predicted number of workers for region $i$ at time $t$ using a linear trend line. A lower value of $R E I_{i}$ indicate a stable economy over the period of 2000 to 2014 .

As reviewed by Siegel et al. (1995), Dissart (2003), Mack et al. (2007) and Jackson (1984), (2015), there are numerous ways to empirically measure economic diversity like the Herfindahl-Hirschman Index (HHI), the Ogive and the national average. In this analysis, economic diversity is measured as regional employment dispersion using the HHI as follows:

$$
D I V_{i}=\sum_{j=1}^{N}\left(e_{i j} / e_{i}\right)^{2}
$$

where $N$ is the total number of industries in the $i_{t h}$ region, $e_{i j}$ is the number of employment for industry $\mathrm{j}$ in the $i_{t h}$ region and $e_{i}$ is the total number of employment in the $i_{t h}$ region.

According to Equation (3), higher HHI indicates the regional economic structure is specialized, while regions with lower HHI values denote that their economies are industrially diversified. HHI ranges from $1 / \mathrm{N}$ for a perfectly diversified economy to 1 if all employment is concentrated in one industry. Because the regional science literature assumes that diversified economies are stable in their economic performance, the HHI is expected to be positively associated with the dependent variable or REI. Although HHI has been questioned empirically and theoretically in regional science research (see Jackson, 1984, 2015: Wagner and Deller, 1998; Wagner, 2000), this index is still used because it does not require additional data. 
Like previous studies (e.g., Jackson, 1984; Malizia and Ke, 1993; Deller and Watson,2016a; and Hong and Xiao,2016), economic diversity is calculated based on employment data for all counties obtained from County Business Patterns (CBP) for the year 2000. CBP is published annually by the U.S. Census Bureau and contains 2-6 digit NAICS industrial activities in terms of employment, payroll, and number of establishments at different geographical levels, including the whole country, states, counties and zip-code areas. This analysis uses the 3-digit level non-agricultural industries of NAICS (83 sectors) from CBP. To protect the confidentiality of its workforce indicators, the U.S. Census uses a series of suppression flags to represent employment ranges: Flag A represents 0-19 employees; Flag B, 20 to 99; and Flag C, 100 to 249. In an earlier study, Deller and Watson(2016a) used data relating to establishments in CBP where the disclosure rules do not apply. As the sizes of the establishments are unknown, however, an establishment with more than 1,000 employees is treated the same as an establishment with less than 10 workers. To circumvent this situation, employment ranges in the CBP were estimated with Isserman and Westervelts (2006) two-stage method and published online. This study makes use of the complete downloaded data set for the year 2000 for the assessment of regional industrial diversity.

In addition, based on existing empirical literature (e.g., Malizia and Ke, 1993; Trendle, 2006; Deller and Watson, 2016a; Hong and Xiao, 2016), the following control variables are used to capture demographical, economic and physical differences between regions.

- Absolute population change from 2000 to 2014

- Population size

- Percentage of population 25 years or older with a bachelors degree

- Percentage of non-white population

- Northeast dummy variable

- Midwest dummy variable

- South dummy variable

Table 2 displays the description of all the variables. 
[INSERT TABLE 2]

\subsection{Spatial regression models}

Based on Table 1, various techniques have been used to explore the effects of economic diversity on regional economic performance, such as bivariate techniques(Jackson, (1984); Attaran, 1986), ordinary and weighted least squares regression (Kort, 1981; Malizia and Ke, 1993), spatial lag and error models (Trendle, 2006) and spatial Durbin model (Deller and Watson,2016a). Because Trendle (2006) and Deller and Watson (2016a) have confirmed the existence of spatial spillovers in the diversity-stability relationship, spatial econometric models are preferred in this analysis.

Traditionally, the standard ordinary least-squares (OLS) regression estimates the dependent variable, which is the regional instability index as a linear combination of industry diversity and a set of controlled variables:

$$
y=X \beta+\varepsilon
$$

where $X$ is a matrix of observations on the explanatory variables; $\beta$ is a vector of estimated parameters; and $\varepsilon$ is a vector of error terms. To incorporate spatial dependence effects, the OLS model has been extended into three basic spatial regression models, namely spatial autoregressive model (SAR), spatial error model (SEM) and spatial Durbin model (SDM). Features of these models are introduced as follows.

First, the spatial lag model, or spatial autoregressive model, hypothesizes that the dependent variable at a particular location can be explained not only by the independent variables but also by the dependent variable values of neighbors. The spatial autoregressive model is formulated as:

$$
y=\rho W y+X \beta+\varepsilon
$$

or in reduced form as:

$$
y=(I-\rho W)^{-1} X \beta+(I-\rho W)^{-1} \varepsilon
$$

where $y$ is the dependent variable for region $\mathrm{i}(\mathrm{i}=1, \ldots, \mathrm{N}), X$ is a matrix of explanatory variables, $\beta$ is a vector of estimated coefficients; $\rho$ is a coefficient describes the strength of the spatial autocorrelation; and $\varepsilon$ is the 
error term. The term $W$ denotes the spatial weight matrix and reflects the geographic relationship between regions. There are various methods used to specify the spatial weight matrix, including distance-based (k-nearest neighbors and threshold distance) and contiguity-based (queen and rook contiguity). The most commonly used criterion is queen contiguity in which two regions, $i$ and $j$, are neighbors if they share at least one point on their boundaries (e.g., the Four Corners Region between Arizona, Colorado, New Mexico and Utah). The corresponding element in the spatial weight matrix $W_{i j}$ is 1 if they are neighbors, otherwise $W_{i j}$ equals 0 .

Second, the spatial error model (SEM) assumes that the dependent variable is determined by a set of explanatory variables and that the error terms are spatially correlated. The SEM model can be written as follows:

$$
y=X \beta+\varepsilon, \varepsilon=\rho W \varepsilon+\mu
$$

or in reduced from as:

$$
y=X \beta+(I-\rho W)^{-1} \mu
$$

The term $\rho$ denotes the spatial autocorrelation term that reflects the interdependence between the regression residuals.

Third, the spatial Durbin model (SDM) posits that the dependent variable can be explained by independent variables, spatially lagged independent, and dependent variables. The model extends the SAR model by incorporating spatially lagged independent variables. The model is expressed as:

$$
y=\rho W y+X \beta+W X \theta+\varepsilon
$$

or in reduced form as:

$$
y=(I-\rho W)^{-1} X \beta+(I-\rho W)^{-1} W X \theta+(I-\rho W)^{-1} \varepsilon
$$

Similarly, the $\theta$ term is a scalar parameter and $\rho$ is a scalar spatial autocorrelation coefficient on the dependent variable. The term $W X \theta$ denotes the weighted average value of the neighboring regions on the independent and control variables. 
A number of tests can be used for model specification in this analysis, including the Lagrange Multiplier (LM) error and lag tests, robust versions of these tests and the likelihood ratio (LR) tests. The LM tests can be used to test whether the spatial lag and error terms are statistically significant when comparing to the OLS model. Based on Florax et al (2003), if the LM error test is significant while the LM lag is not, then the SEM model is used; conversely, if the LM lag test is significant but the LM error is not, then the SAR model is preferred. When both of the LM error and lag tests are significant, the robust LM tests are used. If the robust LM error statistic is greater than the robust LM lag statistic, then the SEM model is used; otherwise, the SAR model is used. Further, the LR tests examine whether the SAR or the SEM can be extended to the SDM model. According to Elhorst (2014), $H_{0}: \theta=0$ examines whether the SDM model can be simplified to the SAR, and $H_{0}: \theta+\delta \beta=0$ tests whether the SDM model can be simplified to the SEM. If both hypotheses are rejected, the SDM is preferred. Otherwise, if the first hypothesis cannot be rejected and the (robust) LM tests prefer the SAR model, then the SAR model best describes the data. Similarly, if the second hypothesis cannot be rejected and the (robust) LM tests favor the SEM model, the SEM model best describes the data.

\section{Empirical Results}

\section{[INSERT TABLE 3}

As shown in Table 3, the LM test results from Models 1-5 suggest that the non-spatial models are less appropriate than the spatial ones. Specifically, the LM tests of Model 1 reject both the hypothesis of no spatially dependent variable as well as the hypothesis of no spatial autocorrected error term. The result of robust LM tests seems to indicate that the SAR model is more appropriate for Model 1 than it is for the non-spatial model. To further investigate which spatial model offers the best fit or whether the SDM model could be simplified into the SAR or SEM model, one may perform the likelihood ratio (LR) tests. In the case of Model 1, the LR tests indicate that the SDM best describes the data. By comparison, in Model 2 the LM tests suggest using the SAR instead of the SEM, whereas the LR tests indicate the SDM is preferred over the SAR model. The LM tests for 
Model 3 seem to show that the SAR is a better fit for describing the data, whereas the LR tests indicate that the SDM can be simplified into the SAR. Thus, the SAR model is used in Model 3. Next, the LM tests for Model 4 suggest a preference for the SEM over the SAR model. The LR tests recommend using the SDM rather than the SEM model. Finally, the LM tests indicate that the SEM better explains the data than does the SAR model. If the statistical significance is set at a $10 \%$ level, the LR tests imply rejecting the SEM model in favor of the SDM one.

\section{[INSERT TABLE 4]}

Table 4 displays the model specification as well as the estimation results. Focusing only on the independent and dependent variables, there are several interesting findings here. First, the coefficients of the diversity independent variable are basically consistent with the theoretical assumption; namely, with the exception of Model 2, the relationship between HHI and regional economic instability is positive and significant. Second, the effect of diversity on regional economic instability varies considerably with different geographical scales. When counties are spatially aggregated into the Economic Areas, the coefficient of the diversity variable increases from 0.171 to 0.691. Similarly, this coefficient increases from 0.164 to 0.480 when metrocounties are combined into MSAs. By comparison, the diversity-instability relationship becomes insignificant in the state-level analysis. Third, the decision whether to include non-metropolitan regions into the analysis does not seem to affect the modeling results very much. Specifically, when non-metro regions are excluded from Models 1 to 4, the diversity coefficient decreases only from 0.171 to 0.164 . Likewise, when comparing Models 3 and 5, the exclusion of rural regions results in a slight decline in the diversity coefficient from 0.691 to 0.480 . Fourth, in terms of spatial components, the spatially lagged independent variable is not always significant, whereas the coefficient of the spatially lagged dependent variable is statistically significant in all models, implying that spatial spillover effects exist in the dependent variable.

\section{[INSERT TABLE 5}

Following LeSage and Pace (2009), the direct and indirect effects of industrial diversity on regional economic instability are estimated in Table 5. 
The estimation results suggest that both direct and indirect effects are positive, implying that industrial diversity contributes to regional economic stability, although some of these effects are not significant. To be more specific, for the county-level data, industrial diversity in general has both a positive local effect and a positive spillover effect in Model 1. Most of the economic contribution comes from the spillover effect. In the case of metro-counties in Model 4, the local effect is significant while the spillover effect is insignificant. When it comes to the state-level analysis in Model 2, both direct and indirect effects are insignificant. Finally, for the EAs and the MSAs, both direct and indirect effects are significant and most of the economic contribution is achieved through local rather than spatial spillovers.

\section{Discussioin}

The results of this analysis confirm not only that economic diversity is positively associated with employment stability but also that spatial dependence exists in the diversity-stability relationship no matter what geographical unit is used. The results also show that the effect of diversity can vary greatly when different geographical units are used. As this variation can possibly impact our understanding of regional economic structures as well as economic development policies, it becomes necessary to choose an appropriate geographical unit to effectively measure regional economic structures. In the remainder of this section, some concerns about the choice of geographical units are discussed along the analytical dimensions of (1) overall size, (2) functional region, (3) full coverage, and (4) temporal variation.

First, the analytical unit should be large enough to quantify economic structure effectively as it can sometimes be meaningless to study the economic diversity of a region with a small population and low employment. In the case of the U.S. regional economies, such a region could be a census tract, a census block, or even a small county. As shown in the comparisons between disaggregated units (county and metro-county) and aggregated units (EA and MSA) in Tables 4 and 5, county-based data sets may not yield intuitive inferences on the effect of economic diversity. From a broader perspective, the size of the analytical unit is related to the scale problem in the MAUP and the UGCoP. For a given spatial extent, the total number of geographi- 
cal units should not be too large, and it is not recommended to use highly disaggregated or too small geographical units to effectively measure regional industry structure.

Second, functional regions rather than formal regions should be used as the analytical unit to study industrial diversity. In the analysis above, as spatial interactions are reduced between functional regions, the estimated effect of diversity on employment stability is stronger when functional regions (EAs and MSAs) rather than formal regions (states) are used. Meanwhile, the proportion of direct diversity effect is higher for functional regions than for formal regions as reflected in Table 5. Similarly, as shown in Table 3 , the spatial spillovers of the diversity variable in Models 3 and 5 are not significant as they are in Models 1, 2 and 4. In that sense, when formal regions are used as the analytical unit, the diversity-stability relationship might not be fully revealed, resulting in ineffective regional economic development policies. In essence, EA, MSA and state data are all spatially aggregated based on county-level data but with different spatial aggregation schemes. These schemes relate to the zoning problem in the MAUP. As functionally aggregated regions are less affected by the MAUP, they are better able to represent regional economic structure than are formal regions. For this reason, functional regions might be the preferred approach to industrial diversity research.

Third, full coverage does not seem to seriously impact the effect of diversity on regional economic stability as long as the geographical units are sufficiently large in population and employment. As discussed previously, metro-counties and MSAs do not cover the whole country, while counties, states and EAs do. The relationship between diversity and instability is significant among metro-counties and MSAs, and this relationship remains significant when non-metro regions are added into metro-counties and MSAs. In part, this is because the stability-diversity relationship still exists in some non-metro regions that are sufficiently large to constitute functional economic systems. However, the term "large" is somewhat vague here because there are no standards to differentiate whether a region is large enough to effectively measure regional economic systems. The metro/non-metro dichotomy in the U.S. does not appear to be a meaningful differentiating mechanism.

Fourth, potential temporal variations in the boundaries of functional 
economic regions should also be considered. In this analysis, county-level data are spatially aggregated to form MSA- and EA-level data. In the case of MSAs, their boundaries may vary from year to year due to possible changes in population and commuting flows. To reflect these variations, the U.S. Office of Management and Budget regularly updates the boundaries of MSAs. Likewise, the boundaries of Economic Areas can be affected; the BEA redefined these boundaries on a regular basis until 2014 when the process was no longer supported because of reductions in government funding . Hence, these outdated EA boundaries might not be used to delimit regional economic systems for recent years. More generally, this time consistency issue has been discussed as the ecological fallacy in a temporal context by Duque et al. (2006). To solve this issue, methods for defining functional regions in spatial analysis such as Farmer and Fotheringham (2011) and Kropp and Schwengler(2016) might provide a solution. However, these methods can generate diverse spatial aggregation schemes for a given spatial extent, and governments and economic development agencies might choose different spatial schemes to analyze economic data. In this regard, coordination might become inefficient. Conversely, the boundaries of Economic Areas were officially delimited by the Bureau of Economic Analysis, and EA-level data were collected, reported and analyzed widely in modeling regional economic structures like Keinath (1985) and Porter (2003). It is proposed that to provide a shared spatial aggregation scheme that assists in the coordination and cooperation between governments and economic development organizations, the Bureau of Economic Analysis should continue supporting the redefinition of Economic Areas.

\section{Policy Implications}

Although economic interactions are smaller between functional than between formal regions, interactions still exist in the form of spatial spillovers. Thus, encouraging economic diversity in neighboring areas can benefit ones own economic performance, and collaboration across functional region boundaries is recommended. However, instead of collaboration between regions, competitions and bidding wars for local economic development frequently occur. For example, a number of cities in Canada and the United States recently expressed their interest in recruiting Amazons second headquarters, 
or Amazon HQ2 (Wingfield and Cohen, 2017). As the high tech company promised to invest as much as $\$ 5$ billion in constructing its headquarters and create at least 50,000 high-paying jobs, Amazon HQ2 is attractive to local governments and economic development agencies, and consequently, a $\$ 5$ billion bidding war broke out. According to Amazon (2017), within one month (October 2017), 238 proposals were submitted by cities and regions from 54 states, provinces, districts and territories to the company. Regional scholars are familiar with such wars, and studies of economic structure have focused already on the competition and complementarity in regional economic development (See Jackson and Sonis, 2001; Healy and Jackson, 2001). Healy and Jackson (2001), for example, suggested that if regions would work with rather than work against each other, costs of competition for local economic development could be avoided and economic returns of investment could be enhanced.

Further, to promote efficient coordination between regions and leverage advantages of different regions in economic development, it is necessary to have an in-depth understanding of the unique characteristics of local economic structures as well as an understanding of the responsibility of governments. In particular, Frenken et al. (2007) and Hong and Xiao (2016) suggested that local governments should recruit industries that are strongly linked to local specializations rather than "popular sectors" or "advanced sectors." Furthermore, functional regions in the U.S. are not always administrative units and the authority of local governments can vary greatly. For example, the basic unit of local government in six New England states is the town; counties have less government authority. Thus, New England towns play a more active role than the counties in economic development coordination.

Finally, together with Deller and Watsons (2016a) findings on rural areas, this empirical analysis indicates that the assumed diversity-stability relationship might also exist among non-metro areas. The implication here is that some rural regions can collaborate with both rural and urban areas to promote their industrial mix, while for smaller regions, it is difficult to measure meaningfully their economic structures, and industrial diversity may not play an active role in their economic development policymaking. Instead, other economic development policy tools should be considered. 


\section{Conclusion}

In this paper, the relationship between economic diversity and regional economic stability is analyzed at multiple geographical scales. The choice of geographical scale has been demonstrated here to alter greatly the diversitystability relationship. When deciding on appropriate geographical scale to study regional economic structure, economic planners and regional analysts should consider the following analytical dimensions, including:

- Are the analytical units large enough in population and employment to meaningfully quantify regional economic structures?

- Are the analytical units functionally aggregated regions?

- Are potential temporal variations in the boundaries of regional economic systems considered?

Table 6 summarizes several geographical units used in the analysis to explore these dimensions. Note that full coverage and metro-county are intentionally left out as full coverage does not greatly impact the effect of diversity and metro-counties are used as a control group of full coverage in the empirical analysis. As shown in Table 6, metropolitan statistical areas are a good choice for effectively quantifying regional economic structure as MSAs (1) are large enough to meaningfully measure economic structures, (2) are functional regions so that spatial economic interactions can be represented better than in formal regions; and (3) are updated regularly so that their boundaries reflect potential temporal changes in regional economic systems. By comparison, Economic Areas cannot be used to study recent regional economic structures; states are subject to criticism because of the MAUP and the UGCoP, and some counties might be too small in population and employment size.

\section{[INSERT TABLE 6}

Generally, this analysis confirms the advantages of functional regions over formal regions in modeling economic systems as suggested by Jackson (1984), Malizia and Ke (1993), Trendle (2006)) and others. It further stresses the possible changes in the boundaries of functional regions and ad-

vocates that the Bureau of Economic Analysis should support the update of 
the Economic Area boundaries for development coordination and cooperation purposes. In addition, it is also suggested that geographical units that are too disaggregated and should not be used to measure regional economic structure.

There are a few potential directions for future research. While this analysis is based on U.S. regional economies because of data availability, its focus on geographical scale can be applied to other countries as well. Extending the research into developing countries like China, for example, might provide additional insights into the role of geographical scale issues both in the analytical and the policy aspects of regional economic development. As the disaggregated geographical units or lower level units (counties) are often nested within the upper level units (states and EAs), future research might also consider using spatial hierarchical models such as Dong et al. (2015) and Lacombe and McIntyre (2017) to study the scale and scope issues in the diversity-stability relationship. 


\section{References}

Amazon (2017). Amazon HQ2. https://www.amazon.com/gp/browse. html/?node=17044620011. Accessed: 2017-11-30.

Attaran, M. (1986). Industrial Diversity and Economic Performance in U.S. Areas. The Annals of Regional Science, 20(2):44-54.

Brown, L. A. and Holmes, J. (1971). The Delimitation of Functional Regions, Nodal Regions, and Hierarchies by Functional Distance Approaches. Journal of Regional Science, 11(1):57-72.

Chiang, S.-h. (2009). The effects of industrial diversification on regional unemployment in taiwan: Is the portfolio theory applicable? Annals of Regional Science, 43(4):947-962.

Conroy, M. E. (1975). The Concept and Measurement of Regional Industrial Diversification. Southern Economic Journal, 41(3):492-505.

Deller, S. C. and Watson, P. (2016a). Did Regional Economic Diversity Influence the Effects of the Great Recession? Economic Inquiry, 54(4):18241838.

Deller, S. C. and Watson, P. (2016b). Spatial Variations in the Relationship Between Economic Diversity and Stability. Applied Economics Letters, $23(7): 520-525$.

Dissart, J.-C. (2003). Regional Economic Diversity and Regional Economic Stability: Research Results and Agenda. International Regional Science Review, 26(4):423-446.

Dong, G., Harris, R., Jones, K., and Yu, J. (2015). Multilevel Modelling with Spatial Interaction Effects with Application to an Emerging Land Market in Beijing, China. PLoS ONE, 10(6):e0130761-19.

Duque, J. C., Artís, M., and Ramos, R. (2006). The Ecological Fallacy in a Time Series Context: Evidence from Spanish Regional Unemployment Rates. Journal of Geographical Systems, 8(4):391-410.

Elhorst, J. P. (2014). Matlab Software for Spatial Panels. International Regional Science Review, 37(3):389-405. 
Farmer, C. J. Q. and Fotheringham, A. S. (2011). Network-Based Functional Regions. Environment and Planning A, 43(11):2723-2741.

Feser, E., Mix, T., White, M., Poole, K., Markley, D., and Pages, E. (2014). Economic Diversity in Appalachia: Statistics, Strategies, and Guides for Action. Washington DC: Appalachian Regional Commission.

Florax, R. J., Folmer, H., and Rey, S. J. (2003). Specification Searches in Spatial Econometrics: the Relevance of Hendrys Methodology. Regional Science and Urban Economics, 33(5):557-579.

Frenken, K., Van Oort, F., and Verburg, T. (2007). Related Variety, Unrelated Variety and Regional Economic Growth. Regional Studies, 41(5):685697.

Gibson, C. C., Ostrom, E., and Ahn, T. K. (2000). The Concept of Scale and the Human Dimensions of Global Change: a Survey. Ecological Economics, 32(2):217-239.

Goodchild, M. F. (2011). Scale in GIS: an Overview. Geomorphology, 130(1):5-9.

Harvey, D. W. (1968). Pattern, Process, and the Scale Problem in Geographical Research. Transactions of the Institute of British Geographers, 45:71-78.

Healy, R. and Jackson, R. W. (2001). Competition and Complementarity in Local Economic Development: a Nonlinear Dynamic Approach. Studies in Regional \& Urban Planing, 9:21-36.

Hong, S. and Xiao, Y. (2016). The Influence of Multiple Specializations on Economic Performance in U.S. Metropolitan Areas. Sustainability, 8(9):963-17.

Isserman, A. M. (2006). 1.5 Million Missing Numbers: Overcoming Employment Suppression in County Business Patterns Data. International Regional Science Review, 29(3):311-335.

Izraeli, O. and Murphy, K. J. (2003). The Effect of Industrial Diversity on State Unemployment Rate and Per Capita Income. The Annals of Regional Science, 37(1):1-14. 
Jackson, R. W. (1984). An Evaluation of Alternative Measures of Regional Industrial Diversification. Regional Studies, 18(2):103-112.

Jackson, R. W. (2015). Are Industry Clusters and Diversity Strange Bedfellows? Review of Regional Studies, pages 1-17.

Jackson, R. W. and Sonis, M. (2001). On the Spatial Decomposition of Forecasts. Geographical analysis, 33(1):58-75.

Johnson, K. P. (1995). Redefinition of the BEA Economic Areas. Survey of Current Business, 75:75-81.

Johnson, K. P. and Kort, J. R. (2004). 2004 Redefinition of the BEA Economic Areas. Survey of Current Business, 84(11):68-75.

Keinath Jr, W. F. (1985). The Spatial Component of the Post-Industrial Society. Economic Geography, 61(3):223-240.

Kort, J. R. (1981). Regional Economic Instability and Industrial Diversification in the US. Land Economics, 57(4):596.

Kropp, P. and Schwengler, B. (2016). Three-Step Method for Delineating Functional Labour Market Regions. Regional Studies, 50(3):429-445.

Kwan, M.-P. (2012). The Uncertain Geographic Context Problem. Annals of the Association of American Geographers, 102(5):958-968.

Lacombe, D. J. and McIntyre, S. G. (2017). Hierarchical Spatial Econometric Models in Regional Science. In Jackson, R. W. and Schaeffer, P. V., editors, Regional Research Frontiers - Vol. 2, pages 151-167. Springer, Cham, Cham, Switzerland.

LeSage, J. P. and Pace, R. K. (2009). Introduction to Spatial Econometrics. CRC Press, Boca Raton, FL.

Mack, E. A., Grubesic, T. H., and Kessler, E. (2007). Indices of Industrial Diversity and Regional Economic Composition. Growth and Change, $38(3): 474-509$.

Malizia, E. E. and Ke, S. (1993). The Influence of Economic Diversity on Unemployment and Stability. Journal of Regional Science, 33(2):221-235. 
Markowitz, H. M. (1968). Portfolio Selection. Efficient Diversification of Investments. Yale University Press, New Haven, CT.

Mizuno, K., Mizutani, F., and Nakayama, N. (2006). Industrial Diversity and Metropolitan Unemployment Rate. The Annals of Regional Science, 40(1):157-172.

Nystuen, J. D. and Dacey, M. F. (1961). A Graph Theory Interpretation of Nodal Regions. Papers of the Regional Science Association, 7(1):29-42.

Openshaw, S. (1984). The Modifiable Areal Unit Problem. GeoBooks, Norwich, UK.

Openshaw, S. and Taylor, P. J. (1979). A Million or So Correlation Coefficients: Three Experiments on the Modifiable Areal Unit Problem. In Wrigley, N., editor, Statistical Applications in the Spatial Sciences, pages 127-144. Pion, London, UK.

Philbrick, A. K. (1957). Principles of Areal Functional Organization in Regional Human Geography. Economic Geography, 33(4):299-336.

Porter, M. E. (2003). The Economic Performance of Regions. Regional Studies, 37(6-7):545-546.

Robinson, W. S. (1950). Ecological Correlations and the Behavior of Individuals. American Sociological Review, 15(3):351.

Ruddell, D. and Wentz, E. A. (2009). Multi-Tasking: Scale in Geography. Geography Compass, 3(2):681-697.

Schaeffer, P. V., Jackson, R. W., and Bukenya, J. O. (2011). Regional science reconsidered. The Review of Regional Studies, 41:161-177.

Siegel, P. B., Johnson, T. G., and Alwang, J. (1995). Regional Economic Diversity and Diversification. Growth and Change, 26(2):261-284.

Simon, C. J. (1988). Frictional Unemployment and the Role of Industrial Diversity. The Quarterly Journal of Economics, 103(4):715-728.

Tobler, W. (1988). Resolution, resampling, and all that. Building databases for global science, 12:9-137. 
Trendle, B. (2006). Regional Economic Instability: the Role of Industrial Diversification and Spatial Spillovers. The Annals of Regional Science, 40(4):767-778.

Wagner, J. E. (2000). Regional Economic Diversity: Action, Concept, or State of Confusion. Journal of Regional Analysis \& Policy, 30(2):1-22.

Wagner, J. E. and Deller, S. C. (1998). Measuring the Effects of Economic Diversity on Growth and Stability. Land Economics, 74(4):541-17.

Watson, M. K. (1978). The Scale Problem in Human Geography. Geografiska Annaler Series B Human Geography, 60(1):36.

Wingfield, N. and Cohen, P. (2017). Amazon Plans Second Headquarters, Opening a Bidding War Among Cities. The New York Times, 7 September. https://www.nytimes.com/2017/09/07/technology/ amazon-headquarters-north-america.html. Accessed: 2017-11-30.

Ye, X. and Rey, S. J. (2011). A Framework for Exploratory Space-Time Analysis of Economic Data. The Annals of Regional Science, 50(1):315339. 


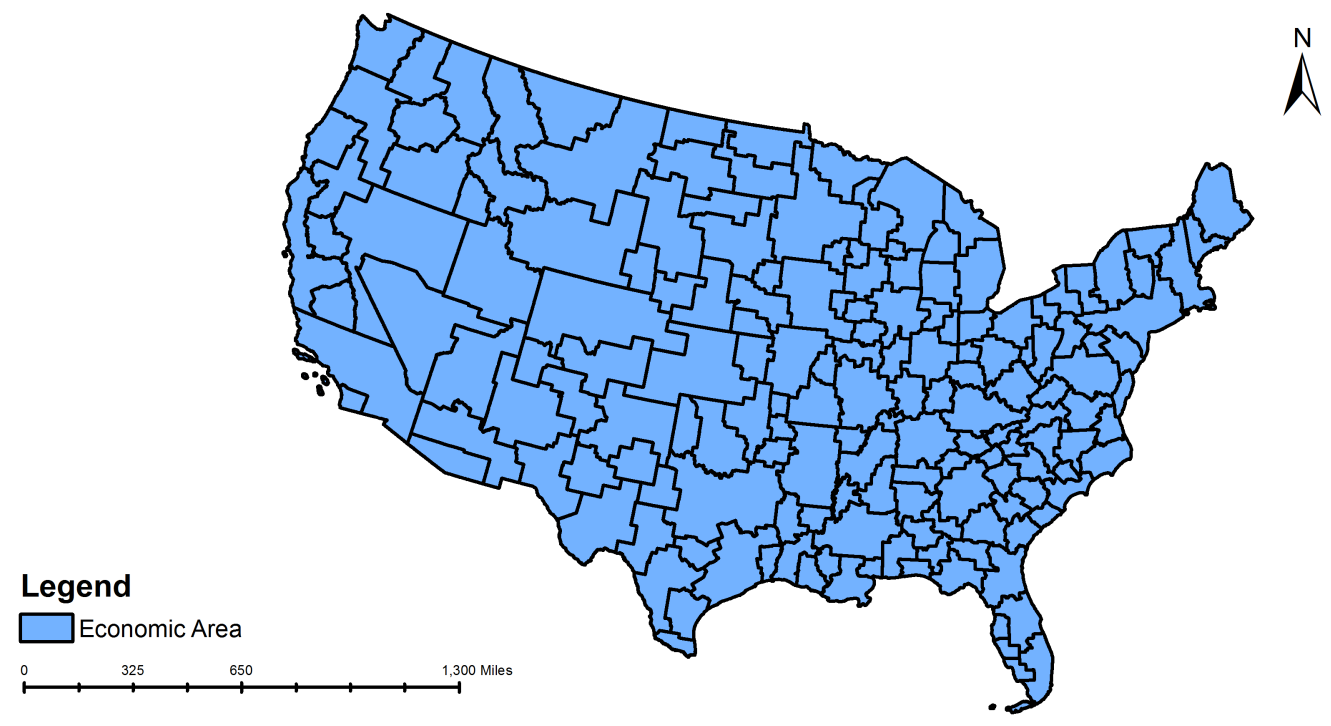

(a)

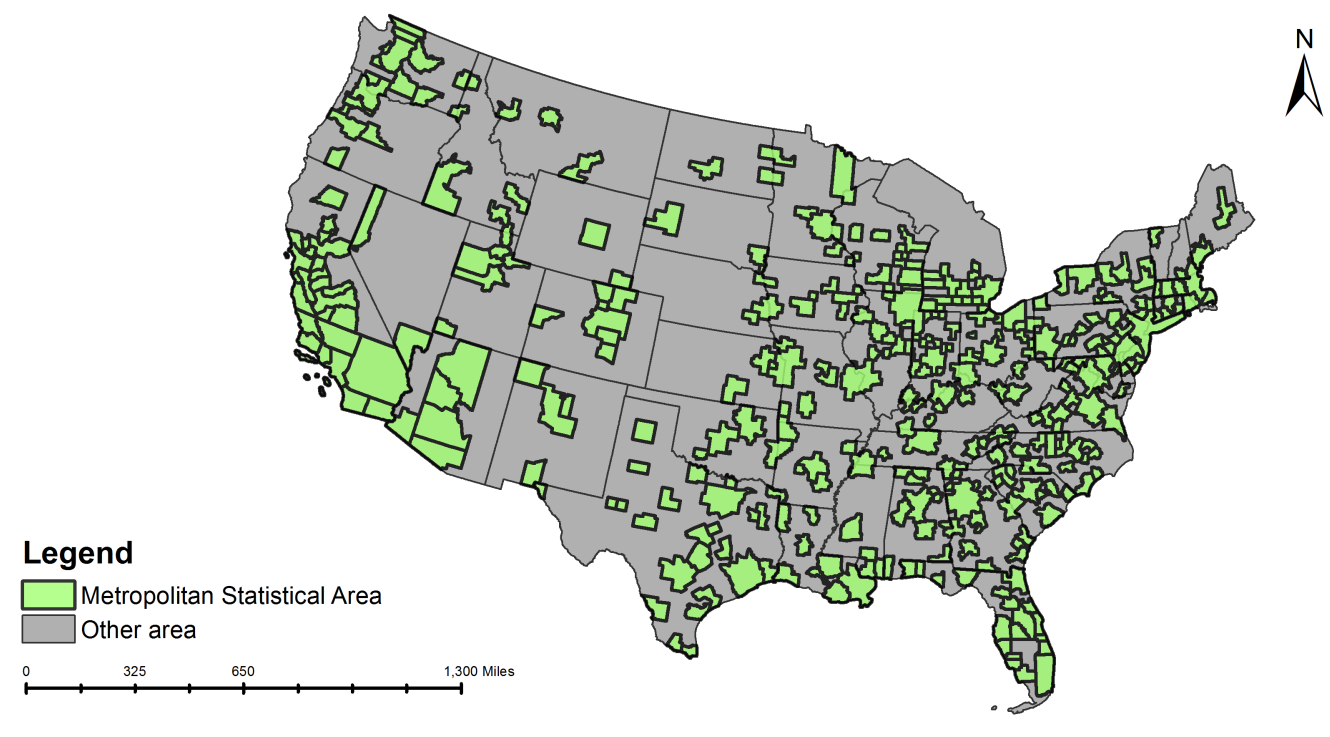

(b)

Figure 1: (a) Economic Areas in the lower U.S. (b)Metropolitan Statistical Areas in the lower U.S.(Source: U.S. Census) 
Table 1: Selective overview of economic diversity research

\begin{tabular}{|c|c|c|c|c|}
\hline Article & Spatial Unit & Diversity Measure & $\begin{array}{l}\text { Modeling } \\
\text { Technique }\end{array}$ & Study Region \\
\hline $\begin{array}{l}\text { Kort } \\
(1981)\end{array}$ & MSA & $\begin{array}{l}\text { Entropy, national } \\
\text { average, ogive, and } \\
\text { percentage of durable } \\
\text { goods }\end{array}$ & $\begin{array}{c}\text { Ordinary and } \\
\text { weighted least } \\
\text { squares }\end{array}$ & $\begin{array}{l}106 \text { MSAs in } \\
\text { the U.S. }\end{array}$ \\
\hline $\begin{array}{l}\text { Jackson } \\
(1984)\end{array}$ & $\begin{array}{l}\text { County } \\
\text { group }\end{array}$ & $\begin{array}{c}\text { National average, } \\
\text { ogive, portfolio } \\
\text { variance and } \\
\text { percentage of durable } \\
\text { goods }\end{array}$ & $\begin{array}{l}\text { Bivariate } \\
\text { correlation }\end{array}$ & Illinois, U.S. \\
\hline $\begin{array}{c}\text { Attaran } \\
(1986)\end{array}$ & State & Entropy & $\begin{array}{l}\text { Bivariate } \\
\text { correlation }\end{array}$ & U.S. \\
\hline $\begin{array}{l}\text { Malizia } \\
\text { and Ke } \\
(1993)\end{array}$ & MSA & Entropy & $\begin{array}{c}\text { Ordinary and } \\
\text { weighted least } \\
\text { squares } \\
\end{array}$ & All U.S. MSAs \\
\hline $\begin{array}{l}\text { Wagner } \\
\text { and Deller } \\
1998\end{array}$ & State & $\begin{array}{c}\text { An input-output based } \\
\text { measure }\end{array}$ & $\begin{array}{c}\text { Ordinary least } \\
\text { squares }\end{array}$ & U.S. \\
\hline $\begin{array}{l}\text { Trendle } \\
(2006)\end{array}$ & $\begin{array}{c}\text { Local } \\
\text { government } \\
\text { area }\end{array}$ & Entropy & $\begin{array}{c}\text { Spatial lag } \\
\text { and error } \\
\text { models }\end{array}$ & $\begin{array}{c}\text { Queensland, } \\
\text { Australia }\end{array}$ \\
\hline $\begin{array}{l}\text { Deller and } \\
\text { Watson } \\
(2016 \mathrm{a})\end{array}$ & County & $\begin{array}{l}\text { Herfindahl, national } \\
\text { average, ogive and } \\
\text { entropy }\end{array}$ & $\begin{array}{c}\text { Spatial } \\
\text { Durbin model }\end{array}$ & U.S. \\
\hline $\begin{array}{l}\text { Hong and } \\
\text { Xiao } 2016\end{array}$ & MSA & $\begin{array}{c}\text { A multiple } \\
\text { specializations } \\
\text { indicator and entropy }\end{array}$ & $\begin{array}{l}\text { Spatial lag } \\
\text { model }\end{array}$ & All U.S. MSAs \\
\hline
\end{tabular}

Note: $\mathrm{MSA}=$ Metropolitan Statistical Area 
Table 2: Description of all the variables

\begin{tabular}{|c|c|c|c|}
\hline Category & Symbol & Description & $\begin{array}{l}\text { Data } \\
\text { Source }\end{array}$ \\
\hline $\begin{array}{l}\text { Dependent } \\
\text { Variable }\end{array}$ & REI & $\begin{array}{l}\text { Average deviation of total } \\
\text { employment from its trend } \\
\text { divided by trend employ- } \\
\text { ment, } 2000-2014\end{array}$ & BEA \\
\hline $\begin{array}{l}\text { Independent } \\
\text { Variable }\end{array}$ & Div & $\begin{array}{l}\text { Indicator of industrial di- } \\
\text { versity using the Herfindahl } \\
\text { Hirschman Index, } 2000\end{array}$ & $\mathrm{CBP}$ \\
\hline \multirow[t]{7}{*}{$\begin{array}{l}\text { Control } \\
\text { Variables }\end{array}$} & Popc & $\begin{array}{l}\text { Absolute value of population } \\
\text { change, } 2000 \text { and } 2014\end{array}$ & Census \\
\hline & Pop & Population size, 2000 & Census \\
\hline & Edu & $\begin{array}{l}\text { Percentage of population } 25 \\
\text { years or older with at least a } \\
\text { bachelors degree, } 2000\end{array}$ & Census \\
\hline & Nonwhite & $\begin{array}{l}\text { Percentage of non-white pop- } \\
\text { ulation, } 2000\end{array}$ & Census \\
\hline & $\mathrm{NE}$ & $\begin{array}{l}\text { Dummy variable for North- } \\
\text { east states }\end{array}$ & Census \\
\hline & South & $\begin{array}{l}\text { Dummy variable for North- } \\
\text { east states }\end{array}$ & Census \\
\hline & MW & $\begin{array}{l}\text { Dummy variable for Midwest } \\
\text { states }\end{array}$ & Census \\
\hline
\end{tabular}

Note: BEA stands for Bureau of Economic Analysis; CBP stands for County Business Pattern. 
Table 3: Lagrange multiplier (LM) and likelihood ratio (LR) tests

\begin{tabular}{c|c|c|c|c|c}
\hline & $\begin{array}{c}\text { Model 1 } \\
\text { (County) }\end{array}$ & $\begin{array}{c}\text { Model 2 } \\
\text { (State) }\end{array}$ & $\begin{array}{c}\text { Model 3 } \\
(\mathrm{EA})\end{array}$ & $\begin{array}{c}\text { Model 4 } \\
\text { (Metro- } \\
\text { County) }\end{array}$ & $\begin{array}{c}\text { Model 5 } \\
(\text { MSA })\end{array}$ \\
\hline LM lag & $714.05^{* * *}$ & $12.56^{* * *}$ & $13.43^{* * *}$ & $47.70^{* * *}$ & 0.22 \\
LM error & $705.96^{* * *}$ & 2.40 & $5.10^{* *}$ & $105.78^{* * *}$ & $23.21^{* * *}$ \\
\hline Robust LM lag & $77.33^{* * *}$ & $13.61^{* * *}$ & $9.70^{* * *}$ & 0.58 & 0.81 \\
Robust LM error & $69.25^{* * *}$ & $3.44^{*}$ & 1.36 & $58.67^{* * *}$ & $23.80^{* * *}$ \\
\hline LR test lag & $251.65^{* * *}$ & $15.89^{* *}$ & 6.90 & $109.02^{* * *}$ & $37.10^{* * *}$ \\
LR test error & $260.72^{* * *}$ & $28.38^{* * *}$ & $15.68^{* *}$ & $53.60^{* * *}$ & $14.53^{*}$ \\
\hline
\end{tabular}

Note: Significance levels: * for $10 \%, * *$ for $5 \%$; *** for $1 \%$ 
$30 / 31$

Table 4: Estimation results of spatial models

\begin{tabular}{|c|c|c|c|c|c|}
\hline & $\begin{array}{l}\text { Model } 1 \\
\text { (County) }\end{array}$ & $\begin{array}{c}\text { Model } 2 \\
\text { (State) }\end{array}$ & $\begin{array}{c}\text { Model } 3 \\
(\mathrm{EA})\end{array}$ & $\begin{array}{l}\text { Model } 4 \\
\text { (Metro- } \\
\text { County) }\end{array}$ & $\begin{array}{c}\text { Model } 5 \\
\text { (MSA) }\end{array}$ \\
\hline Diversity & $\begin{array}{c}0.171^{* * *} \\
(4.895)\end{array}$ & $\begin{array}{c}0.378 \\
(1.480)\end{array}$ & $\begin{array}{c}0.691^{* * *} \\
(4.699)\end{array}$ & $\begin{array}{c}0.164^{* * *} \\
(3.560)\end{array}$ & $\begin{array}{c}0.480^{* * *} \\
(6.392)\end{array}$ \\
\hline Popc & $\begin{array}{c}0.074^{* * *} \\
(3.694)\end{array}$ & $\begin{array}{c}0.086 \\
(1.381)\end{array}$ & $\begin{array}{c}0.100^{* * * *} \\
(3.722)\end{array}$ & $\begin{array}{c}0.098^{* * * *} \\
(2.781)\end{array}$ & $\begin{array}{c}0.130^{* * * *} \\
(5.364)\end{array}$ \\
\hline Pop & $\begin{array}{c}-0.143^{* * *} \\
(-12.233)\end{array}$ & $\begin{array}{c}0.131^{* *} \\
(2.036)\end{array}$ & $\begin{array}{c}0.005 \\
(0.836)\end{array}$ & $\begin{array}{c}-0.210^{* * *} \\
(-9.246)\end{array}$ & $\begin{array}{c}-0.127^{* * *} \\
(-7.674)\end{array}$ \\
\hline Edu & $\begin{array}{c}-0.098^{* * *} \\
(-8.677)\end{array}$ & $\begin{array}{c}-0.869^{* * *} \\
(-2.763)\end{array}$ & $\begin{array}{c}0.013 \\
(0.093)\end{array}$ & $\begin{array}{c}0.015 \\
(0.837)\end{array}$ & $\begin{array}{l}-0.030 \\
(-0.451)\end{array}$ \\
\hline Nonwhite & $\begin{array}{l}-0.052^{*} \\
(-1.916)\end{array}$ & $\begin{array}{c}-0.138 \\
(-1.176)\end{array}$ & $\begin{array}{c}-0.041 \\
(-0.825)\end{array}$ & $\begin{array}{c}-0.007 \\
(-0.224)\end{array}$ & $\begin{array}{c}0.142^{* * *} \\
(3.616)\end{array}$ \\
\hline $\mathrm{NE}$ & $\begin{array}{c}0.119^{* * *} \\
(7.799)\end{array}$ & $\begin{array}{c}-1.124^{* * *} \\
(-2.774)\end{array}$ & $\begin{array}{c}0.273^{* *} \\
(2.342)\end{array}$ & $\begin{array}{c}-0.451^{* * *} \\
(-13.381)\end{array}$ & $\begin{array}{c}-0.159 \\
(-1.064)\end{array}$ \\
\hline South & $\begin{array}{c}0.009 \\
(0.041)\end{array}$ & $\begin{array}{c}-0.755^{* * *} \\
(-2.701)\end{array}$ & $\begin{array}{c}-0.137^{* *} \\
(-2.050)\end{array}$ & $\begin{array}{c}-0.391^{* *} \\
(-2.064)\end{array}$ & $\begin{array}{c}-0.327^{* * *} \\
(-3.488)\end{array}$ \\
\hline MW & $\begin{array}{l}-0.109 \\
(-0.809)\end{array}$ & $\begin{array}{c}-0.372 \\
(-1.505)\end{array}$ & $\begin{array}{c}-0.224 * * * \\
(-2.874)\end{array}$ & $\begin{array}{c}-0.379 * * * \\
(-2.641)\end{array}$ & $\begin{array}{c}-0.115 \\
(-1.277)\end{array}$ \\
\hline $\mathrm{W}^{*}$ Diversity & $\begin{array}{c}0.074 \\
(0.627)\end{array}$ & $\begin{array}{c}0.229 \\
(0.412)\end{array}$ & N.A. & $\begin{array}{c}0.067 \\
(0.491)\end{array}$ & $\begin{array}{c}0.180 \\
(1.467)\end{array}$ \\
\hline $\mathrm{W}^{*} \mathrm{Popc}$ & $\begin{array}{c}0.019 \\
(0.435)\end{array}$ & $\begin{array}{c}0.140 \\
(0.968)\end{array}$ & N.A. & $\begin{array}{c}0.001 \\
(0.020)\end{array}$ & $\begin{array}{l}-0.045 \\
(-1.290)\end{array}$ \\
\hline $\mathrm{W}^{*} \mathrm{Pop}$ & $\begin{array}{c}0.101^{* * *} \\
(6.969)\end{array}$ & $\begin{array}{c}-0.169 \\
(-1.627)\end{array}$ & N.A. & $\begin{array}{c}0.107^{* * *} \\
(5.444)\end{array}$ & $\begin{array}{c}0.085^{* * *} \\
(3.324)\end{array}$ \\
\hline $\mathrm{W}^{*} \mathrm{Edu}$ & $\begin{array}{c}0.256^{* * *} \\
(13.774)\end{array}$ & $\begin{array}{c}0.185 \\
(0.204)\end{array}$ & N.A. & $\begin{array}{c}0.097^{* * * *} \\
(5.351)\end{array}$ & $\begin{array}{l}-0.087 \\
(-0.904)\end{array}$ \\
\hline $\mathrm{W}^{*}$ Nonwhite & $\begin{array}{c}0.091^{* *} \\
(2.297)\end{array}$ & $\begin{array}{c}0.368 \\
(1.599)\end{array}$ & N.A. & $\begin{array}{c}0.063 \\
(1.289)\end{array}$ & $\begin{array}{c}-0.105^{* *} \\
(-2.024)\end{array}$ \\
\hline $\mathrm{W}^{*} \mathrm{NE}$ & $\begin{array}{c}-0.154^{* * *} \\
(-7.658)\end{array}$ & $\begin{array}{l}1.404^{* *} \\
(2.492)\end{array}$ & N.A. & $\begin{array}{l}0.276^{* * *} \\
(10.143)\end{array}$ & $\begin{array}{c}-0.126 \\
(-0.756)\end{array}$ \\
\hline $\mathrm{W}^{*}$ South & $\begin{array}{c}0.033 \\
(0.145)\end{array}$ & $\begin{array}{c}0.432 \\
(1.294)\end{array}$ & N.A. & $\begin{array}{l}0.328^{*} \\
(1.166)\end{array}$ & $\begin{array}{l}0.178^{*} \\
(1.732)\end{array}$ \\
\hline $\mathrm{W}^{*} \mathrm{MW}$ & $\begin{array}{c}0.124 \\
(0.895)\end{array}$ & $\begin{array}{c}0.440 \\
(0.972)\end{array}$ & N.A. & $\begin{array}{c}0.276^{*} \\
(1.883)\end{array}$ & $\begin{array}{c}-0.136 \\
(-1.350)\end{array}$ \\
\hline$\rho$ & $\begin{array}{c}0.499^{* * *} \\
(4.026)\end{array}$ & $\begin{array}{l}0.333^{* *} \\
(2.016)\end{array}$ & $\begin{array}{c}0.331^{* * *} \\
(3.953)\end{array}$ & $\begin{array}{c}0.302^{* * *} \\
(2.186)\end{array}$ & $\begin{array}{c}0.234^{* * *} \\
(4.666)\end{array}$ \\
\hline Sample size & 3079 & 49 & 170 & 1066 & 359 \\
\hline R-squared & 0.21 & 0.55 & 0.43 & 0.32 & 0.24 \\
\hline Log-likelihood & -668.34 & 12.88 & 1.94 & -197.47 & -30.49 \\
\hline
\end{tabular}

Notes: (1) With the exception of the dummy variables, all variables are measured as natural logs. (2) Numbers in the parentheses represent t-statistics values. (3) Significance levels: ${ }^{*}$ for $10 \%,{ }^{*}$ for $5 \%$; $* * *$ for $1 \%$. 
Table 5: Estimation of direct, indirect and total effects

\begin{tabular}{c|c|c|c|c|c}
\hline & $\begin{array}{c}\text { Model 1 } \\
\text { (County) }\end{array}$ & $\begin{array}{c}\text { Model 2 } \\
\text { (State) }\end{array}$ & $\begin{array}{c}\text { Model 3 } \\
(\mathrm{EA})\end{array}$ & $\begin{array}{c}\text { Model 4 } \\
\text { (Metro- } \\
\text { County) }\end{array}$ & $\begin{array}{c}\text { Model 5 } \\
\text { (MSA) }\end{array}$ \\
\hline Model type & SDM & SDM & SAR & SDM & SDM \\
\hline Direct effect & $0.184^{* * *}$ & 0.414 & $0.707^{* * *}$ & $0.170^{* * *}$ & $0.510^{* * *}$ \\
& $(4.883)$ & $(1.547)$ & $(4.804)$ & $(3.520)$ & $(6.898)$ \\
Indirect effect & $0.272^{*}$ & 0.463 & $0.325^{* * *}$ & 0.130 & $0.353^{* * *}$ \\
& $(1.757)$ & $(0.495)$ & $(2.909)$ & $(0.838)$ & $(2.461)$ \\
Total effect & $0.456^{* * *}$ & 0.878 & $1.033^{* * *}$ & $0.301^{*}$ & $0.864^{* * *}$ \\
& $(2.654)$ & $(0.825)$ & $(5.005)$ & $(1.725)$ & $(5.045)$ \\
\hline
\end{tabular}

Notes: (1) Numbers in the parentheses represent t-statistics values. (2) Significance levels: * for $10 \%, * *$ for $5 \%$; *** for $1 \%$

Table 6: Summary of analytical units through the three analytical dimensions

\begin{tabular}{c|c|c|c}
\hline $\begin{array}{c}\text { Geographical } \\
\text { Unit }\end{array}$ & $\begin{array}{c}\text { (1) Large } \\
\text { Enough? }\end{array}$ & $\begin{array}{c}\text { (2) Functionally } \\
\text { Aggregated? }\end{array}$ & $\begin{array}{c}\text { (3) Consider } \\
\text { Temporal } \\
\text { Consistency? }\end{array}$ \\
\hline County & $?$ & & $\boldsymbol{\checkmark}$ \\
\hline State & $\boldsymbol{V}$ & & $?$ \\
\hline Economic Area & $\boldsymbol{V}$ & $\boldsymbol{V}$ \\
\hline MSA & $\boldsymbol{V}$ & $\boldsymbol{V}$ & \\
\hline
\end{tabular}

Notes: (1) $\boldsymbol{V}=$ Yes; ? = Not Sure. (2) MSA=Metropolitan Statistical Area 